\title{
Treatment of newborn infants with inhaled nitric oxide
}

\author{
R H Mupanemunda, A D Edwards
}

Considerable interest has focused on the use of inhaled nitric oxide (NO) as a specific treatment for refractory hypoxia caused by pulmonary vasoconstriction. The pharmacology and toxicology of NO have been reviewed in the previous article, and this one examines the potential therapeutic applications of inhaled NO in the treatment of sick newborn infants.

\section{Rationale for inhalational NO treatment} The therapeutic options for severe hypoxaemia associated with pulmonary hypertension currently include mechanical ventilation and the intravenous administration of pharmacological agents to reduce pulmonary vascular resistance. ${ }^{1}$ However, the effect of intravenous vasodilator drugs is often limited by lack of responsiveness, inability to sustain vasodilation, or harmful side effects. ${ }^{2}$ Efforts to dilate the pulmonary vasculature often result in systemic vasodilation and hypotension, which may worsen coexisting right-to-left shunting. ${ }^{3}$ Within the lung intravenous vasodilators may dilate vessels in non-ventilated lung regions and increase intrapulmonary shunting, further impairing gas exchange. Inhalation of NO aims to introduce a vasodilator stimulus directly to those areas of lung which are ventilated, and avoid exacerbating ventilation:perfusion mismatch, while rapid inactivation of $\mathrm{NO}$ by haemoglobin in the blood will protect the systemic vascular bed from vasodilation and unwanted systemic hypotension. ${ }^{45}$

\section{Indications for NO treatment}

A considerable body of experimental evidence suggests that inhaled NO may be beneficial in disease states characterised by pulmonary vasoconstriction and ventilation:perfusion mismatch. ${ }^{6}$ However, few largescale therapeutic trials have been completed and there is as yet insufficient evidence to conclude that NO is a lifesaving treatment. ${ }^{7}$ Currently the best indication for $\mathrm{NO}$ administration is as part of a clinical trial during intensive treatment for life threatening hypoxaemia associated with one of the many causes of pulmonary vasoconstriction.

\section{PERSISTENT PULMONARY HYPERTENSION OF} THE NEWBORN

Infants with idiopathic persistent pulmonary hypertension of the newborn (PPHN) have an anatomically normal heart. They present soon after birth with cyanosis due to right-to-left shunting through the ductus arteriosus and foramen ovale. ${ }^{89}$ PPHN can be secondary to perinatal hypoxia, sepsis, meconium aspiration, diaphragmatic hernia, congenital heart disease, severe respiratory distress syndrome or polycythaemia. ${ }^{1}$

Specific treatments include intravenous vasodilators, hyperventilation, high frequency oscillatory ventilation and extracorporeal membrane oxygenation. ${ }^{1}$ Intravenous vasodilators such as tolazoline, ${ }^{10}$ prostacyclin, ${ }^{11}$ and magnesium sulphate, ${ }^{12}$ can produce unpredictable responses and may lead to systemic hypotension or increased intrapulmonary shunting. ${ }^{10}$ The value of hyperventilation has been questioned because of the respiratory morbidity ${ }^{13} 14$ and potential neurological sequelae. ${ }^{15}$ It has recently been suggested that high frequency oscillatory ventilation may be effective. ${ }^{16}$ These treatments have not yet been subjected to critical analyses in controlled trials.

Although the causal mechanism of PPHN is not known, several recent reports have provided additional information on the pathophysiology of the disorder. Enhanced activity of endogenous NO has been shown to contribute to the normal decline in pulmonary vascular resistance at birth. ${ }^{17} \mathrm{~A}$ decreased production of endogenous NO may contribute to the failure of postnatal pulmonary vascular adaptation seen in PPHN: hypoxia ${ }^{18}$ and hypertension, ${ }^{19}$ which characterise PPHN, are known to inhibit the release of endogenous $\mathrm{NO}$, and a lower synthetic rate of $\mathrm{NO}$ has been reported during the acute phase of PPHN. ${ }^{20}$ Furthermore, L-arginine, a substrate for NO synthesis, may be deficient in some infants with PPHN. ${ }^{21}$ Thus inhaled NO treatment may circumvent a deficiency in the two substrates for NO synthesis, oxygen and L-arginine, and supply the vasodilator directly to the pulmonary vasculature.

Two preliminary studies have shown that inhaled NO is effective in reversing the hypoxaemia due to PPHN. Inhaled NO at a dose of $80 \mathrm{ppm}$ with an inspired oxygen fraction of 0.9 raised the mean postductal oxygen tension from $5.4 \mathrm{kPa}$ to $15.4 \mathrm{kPa}$ within 10 minutes. ${ }^{22}$ Thirteen of 15 infants with severe PPHN were successfully treated with $6 \mathrm{ppm} \mathrm{NO} .^{23}$ In one patient 30 minutes of treatment produced a permanent improvement in gas exchange and resolution of PPHN, and another received prolonged NO treatment for 23 days (median concentration $20 \mathrm{ppm}$ ) which permitted a sustained improvement in oxygenation. ${ }^{22}$ In an 
open multicentre trial involving over 100 term and preterm infants a French group reported similar success in treating PPHN with 10-80 ppm NO. ${ }^{24}$

\section{CONGENITAL HEART DISEASE}

Pulmonary vascular disease is a serious complication of congenital heart disease. In infants with this condition pulmonary endothelial cells are morphologically abnormal, and endothelial dysfunction is evident even before any morphological changes become apparent. ${ }^{25}$ Furthermore, congenital heart disease is often complicated by hypertensive crises, especially following open heart surgery, when pulmonary arterial pressure can rise swiftly to exceed the systemic arterial pressure, so that left atrial return falls and cardiac output rapidly declines ${ }^{26}$; transient endothelial dysfunction due to endothelial damage is thought to contribute to these crises. ${ }^{27}$ The condition is difficult to reverse, and a substantial part of postoperative morbidity and mortality is related to these crises. ${ }^{28}$

Pulmonary hypertensive crises characteristically occur in infants who had a high pulmonary blood flow preoperatively. Miller et al have demonstrated that chronic increases in blood flow augment endothelium derived relaxing factor (EDRF) activity, ${ }^{29}$ and it is tempting to speculate that these infants may have raised basal endogenous NO release to counteract the raised pulmonary vascular tone. Endothelial damage and dysfunction during surgery (with a concomitant reduction in endogenous NO release) would render these patients more susceptible to a pulmonary hypertensive crisis. ${ }^{30}$

Management has largely consisted of hyperoxic hyperventilation and administration of intravenous vasodilators. ${ }^{31}$ NO inhalation seems to be an effective alternative treatment: $\mathrm{NO}$ at doses as little as $1 \mathrm{ppm}$ has been successful in treating pulmonary hypertensive crises. ${ }^{27} 3233$ In infants with congenital heart disease complicated by pulmonary hypertension inhaled $\mathrm{NO}$ at $20-80 \mathrm{ppm}$ effectively reduced the pulmonary arterial pressure. ${ }^{34}$

\section{RESPIRATORY DISTRESS SYNDROME}

Echocardiographic studies have demonstrated increased pulmonary vascular resistance in preterm neonates with respiratory distress syndrome (RDS) which correlated with disease severity and mortality. ${ }^{35-37}$ Severe RDS was associated with a delayed fall in pulmonary artery pressure in the immediate postnatal period, suggesting that high pulmonary vascular resistance may contribute to the mortality of RDS in premature infants. ${ }^{37}$ The extent to which decreased pulmonary production of NO is a mechanism of this pulmonary vasoconstriction is unclear, but endothelial dysfunction is likely to exacerbate any tendency to high pulmonary vascular resistance.

In premature infants with RDS who required an inspired oxygen fraction $\left(\mathrm{FIO}_{2}\right)$ greater than $0 \cdot 6$, brief exposure to $\mathrm{NO}$ at $5-40$ ppm produced significant improvements in oxygenation. ${ }^{38}$ Although these data are preliminary, it is possible that early treatment with inhaled NO in severe RDS may allow reductions in ventilation pressures and $\mathrm{FIO}_{2}$, potentially reducing the injury caused by barotrauma and oxygen toxicity in the susceptible premature lung.

\section{BRONCHOPULMONARY DYSPLASIA}

Bronchopulmonary dysplasia (BPD) is characterised by hypoxia and hypercapnia with pronounced maldistribution of ventilation to perfusion. ${ }^{39}$ Pulmonary hypertension is a frequent and serious complication. ${ }^{40}$ Inhaled NO at a dose of 3-10 ppm was used successfully in treating acute hypoxaemic respiratory failure in six infants with BPD complicated by pneumonia. ${ }^{41}$ All six patients survived and were successfully weaned off NO after periods of up to 20 days of continuous NO inhalation. In another study of six infants with BPD brief inhalation NO treatment at doses of 5-40 ppm significantly improved oxygenation, and prolonged NO inhalation with $\leqslant 10 \mathrm{ppm} \mathrm{NO}$ for up to 52 days did not produce tachyphylaxis. ${ }^{42}$ These observations suggest that inhaled NO improved the ventilation:perfusion relation and reduced intrapulmonary shunting. Inhaled NO may thus potentially represent an alternative approach to treating infants with severe BPD and pulmonary hypertension. However, we have treated four other infants with severe BPD using prolonged inhalational NO treatment, and found that they could not be weaned off NO. Suppression of endogenous nitric oxide synthesis in these infants may have accounted for our observations and this remains a potential risk in conditions requiring prolonged inhalational NO treatment.

\section{OTHER DISORDERS}

Current treatments for acute hypoxaemic respiratory failure are often unsuccessful, with mortality remaining at about $60 \% .{ }^{43} 44$ Acute hypoxaemic respiratory failure is characterised by severe ventilation:perfusion mismatch with pulmonary hypertension. ${ }^{45} 46$ Approaches that improve oxygenation despite lower ventilatory pressures and inspired oxygen concentrations may potentially improve outcome, in part by decreasing secondary lung injury. ${ }^{47} 48$ Rossaint et al reported a survival rate of $80 \%$ when inhaled NO was used to treat adults with adult RDS. ${ }^{5}$ Inhaled NO reduced intrapulmonary shunting and ventilation:perfusion imbalance, improving oxygenation. One study has reported some success in treating 10 paediatric patients with severe adult type RDS using prolonged inhalational NO treatment (up to 24 days) at a concentration of 3-10 ppm. ${ }^{41}$ Another study reported acute improvements in oxygenation and a reduction in pulmonary vascular resistance with brief inhalations of 10-60 ppm NO. ${ }^{49}$ Further work is required to define the potential role of inhaled NO in other pulmonary disorders associated with acute lung injury. ${ }^{50}$ 
Administration of nitric oxide

Administration should embrace a system that: (a) permits continuous accurate measurements of $\mathrm{NO}$ and $\mathrm{NO}_{2}$ concentration in inspired gas; (b) minimises the time of contract between oxygen and NO; and (c) removes $\mathrm{NO}$ and $\mathrm{NO}_{2}$ from exhaled gas. NO should probably only be used when full monitoring facilities (including blood methaemoglobin concentrations) are available, and long term follow up of treatment is carried out.

NO is usually supplied in nitrogen at a variety of concentrations. Stainless steel pressure regulators and flow meters are required along with Teflon tubing for administering the gas into the ventilator circuit, as $\mathrm{NO}$ and $\mathrm{NO}_{2}$ are corrosive. The NO may ideally be fed into the inspiratory limb of the ventilator circuit between the patient manifold and the humidifier. The resulting gas mixture should be sampled downstream of the input port just proximal to the patient manifold.

Monitoring of inhaled NO concentrations should be routine, and several methods are available. A commercial electrochemical system which relies on the oxidation of $\mathrm{NO}+\mathrm{H}_{2} \mathrm{O}$ to $\mathrm{HNO}_{3}+3 \mathrm{e}+3 \mathrm{H}^{+}$has been used by several groups. ${ }^{51}$ Measurement of NO concentration by chemiluminescence depends on oxidising $\mathrm{NO}$ with ozone to give $\mathrm{NO}_{2}$ in an electronically excited state which emits light on returning to the ground state. ${ }^{52}$ Chemiluminescence is highly sensitive and, although costly and more difficult to use, has been effective in many clinical studies.

It is recommended that the exhaust gases be scavenged to avoid any buildup of toxic byproducts which could potentially corrode the ventilator expiratory valve. Exhaust gases may alternatively be passed through carbon and purafil filters, soda lime, or activated charcoal. The exhaust gases may also first be passed through a tube with potassium permanganate coated aluminar beads to convert $\mathrm{NO}$ into $\mathrm{NO}_{2}$ which may then be passed through the filters.

\section{Dose considerations}

Measurement of exhaled gas from normal lungs suggests that endogenous NO concentration in lung approximates to 8 parts per billion $(\mathrm{ppb})^{53}$ and free NO has been found in human plasma at about $3 \mathrm{nM}$ concentrations. ${ }^{54}$ The optimal therapeutic doses of inhaled NO for different disease states are unknown and are likely to vary depending on the pathology.

It is important to optimise ventilator settings before starting treatment with NO. Administration usually begins at $10-20 \mathrm{ppm}$ $\mathrm{NO}$, and this can frequently be reduced to below $10 \mathrm{ppm}$ for maintenance of therapeutic effects. Higher concentrations are effective, and some studies have used $80 \mathrm{ppm}$, although with little added benefit. As most patients will be receiving high fractions of inspired oxygen, NO concentrations in excess of $80 \mathrm{ppm}$ are not currently recommended. ${ }^{55}$ The response is usually immediate but may take up to 15 minutes and infrequently longer. Sudden withdrawal of NO treatment can lead to life threatening hypoxia, and the dose should probably be reduced slowly.

Infants with PPHN have been successfully treated with doses of $6-80 \mathrm{ppm}^{22} 23$ and one study found no difference in response to doses between 5-80 ppm. ${ }^{56}$ Effects have been reported with concentrations as low as $10 \mathrm{ppb}$ in adults with adult RDS. ${ }^{57}$ The lowest effective dose observed in our studies of RDS and BPD was $40 \mathrm{ppb}$ (Mupanemunda et al, unpublished data).

\section{Conclusion}

NO is a promising new treatment. However, largescale trials have yet to define its true value, and until such data are available, administration should properly be restricted to infants enrolled in formally conducted trials. The successful introduction of surfactant treatment offers a challenge to the paediatric community to manage the advent of NO with similar rigour.

1 Greenough A, Morley CJ, Roberton NRC. Acute respiratory disorders in the newborn. In: Roberton NRC, piratory disorders in the newborn. In: Roberton NRC,
ed. Textbook of neonatology. Edinburgh: Churchill ed. Textbook of neonatology.
Livingstone, 1992: 432-51.

2 Stevenson DK, Kasting DS, Darnall RA. Refractory hypoxaemia associated with neonatal pulmonary disease: the use and limitations of tolazoline. $\mathcal{F}$ Pediatr 1979; 95: 595-9.

3 Jones DK, Higgenbottam TW, Wallwork J. Treatment of primary pulmonary hypertension with intravenous epoprostenol (prostacyclin). Br Heart $\mathcal{f}$ 1987; 57: 270-8.

4 Frostell C, Fratacci M-D, Wain JC, Jones R, Zapol WM. Inhaled nitric oxide: a selective pulmonary vasodilator reversing hypoxic pulmonary vasoconstriction. Circulation reversing hypoxic pulm

5 Rossaint R, Falke KJ, Lopez F, Slama K, Pison U, Zapol WM. Inhaled nitric oxide for the adult respiratory distress syndrome. N Engl f Med 1993; 328: 399-405.

6 Gaston B, Drazen JM, Loscalzo J, Stamler JS. The biology of nitrogen oxides in the airways. Am Rev Respir Dis 1994; 149: 538-51.

7 Davidson D. No bandwagon, yet. Inhaled nitric oxide (NO) for neonatal pulmonary hypertension. Am Rev Respir Dis 1993; 147: 1078-9.

8 Gersony WN. Persistence of the fetal circulation. A com-

mentary. F Pediatr 1973; 82: 1103-6.
9 Haworth SG, Reid L. Persistent fetal circulation: newly recognised structural features. F Pediatr 1976; 88: 614-20.

10 Benitz WB, Stevenson DK. Refractory neonatal hypoxaemia, diagnostic evaluation and pharmacologic manageaemia, diagnostic evaluation and pha
ment. Resuscitation 1988; 16: 49-64.

11 Kaapa P, Koivisto M, Ylikorkala O, Kouvalainen $\mathrm{K}$. Prostacyclin in the treatment of neonatal pulmonary hypertension. F Pediatr 1985; 107: 951-3.

12 Abu-Osba YK, Galal O, Manasra K, Rejial A. Treatment of severe pulmonary hypertension of the newborn with magnesium sulphate. Arch Dis Child 1992; 67: 31-5.

13 Drummond WH, Gregory GA, Heyman MA, Phibbs RA. The independent effects of hyperventilation, tolazoline and dopamine on infants with persistent pulmonary hypertension. $\mathcal{F}$ Pediatr 1981; 98: 603-11.

14 Wung JT, James LS, Kitchevsky E, James E. Management of infants with severe respiratory failure and persistence of of infants with severe respiratory failure and persistence of
the fetal circulation without hyperventilation. Pediatrics the fetal circulation

15 Bifano EM, Pfannenstiel A. Duration of hyperventilation and outcome in infants with persistent pulmonary hypertension. Pediatrics 1988; 81: 657-61.

16 Clark RH, Yoder BA, Snell MS. Prospective, randomized comparison of high-frequency oscillation and conventional ventilation in candidates for extracorporeal membrane oxygenation. $\mathcal{F}$ Pediatr 1994; 124: 447-54.

17 Abman SH, Chatfield BA, Hall SL, McMurty IF. Role of endothelium-derived relaxing factor during transition of pulmonary circulation at birth. Am f Physiol 1990; 259: H1921-7.

18 Johns RA, Linder JM, Peach MJ. Endothelium-dependent relaxation and cGMP accumulation in rabbit pulmonary relaxation and cGMP accumulation in rabbit pulmonary artery are selectively imp

19 Mayhan WG, Faraci FM, Heistad DD. Impairment of endothelium-dependent responses of cerebral arterioles in chronic hypertension. Am $\mathcal{f}$ Physiol 1987; 253: H1435-40.

20 Castillo L, de Rojas T, Chapman T, Burke JF, Tannenbaum $S$, Young VR. Nitric oxide synthesis is decreased in persistent pulmonary hypertension of the newborn. Pediatr Res 1993; 33: 20 A. 
21 Vosatka RJ, Kashyap S, Trifiletti RR. Arginine deficiency accompanies persistent pulmonary hypertension of the newborn. Biol Neonate 1994; 66: 65-70.

22 Roberts JD, Polaner DM, Lang P, Zapol WM. Inhaled nitric oxide in persistent pulmonary hypertension of the newborn. Lancet 1992; 340: 818-9.

23 Kinsella JP, Neish SR, Ivy DD, Shaffer E, Abman SH. Clinical responses to prolonged treatment of persistent pulmonary hypertension of the newborn with low doses of inhaled nitric oxide. $\mathcal{F}$ Pediatr 1993; 123: 103-8.

24 Storme L, Francoise M, Tahiri C, Zupan V. Inhaled nitric oxide in persistent pulmonary hypertension of the newoxide in persistent pulmonary hyp

25 Hall SM, Haworth SG. Onset and evolution of pulmonary vascular disease in young children: abnormal postnatal remodelling studies in lung biopsies. $\mathcal{F}$ Pathol 1992; 166: 183-94.

26 Jones ODH, Shore DF, Rigby ML. The use of tolazoline hydrochloride as a pulmonary vasodilator in potentially fatal episodes of pulmonary vasoconstriction after cardiac surgery in children. Circulation 1981; 64 (suppl II): 134-9.

27 Wessel DL, Adatia J, Thompson J, Kulih TJ. Inhaled nitric oxide (NO) for the treatment of pulmonary hypertension before and after cardiopulmonary bypass (CPB). Circulation 1992; 86 (suppl 1): 776(A).

28 Hopkins RA, Bull C, Haworth SG, de Laval MR, Stark J. Pulmonary hypertensive crises following surgery for congenital heart defects in

29 Miller VM, Aarhus LL, Vanhoutte PM. Modulation of endothelium-dependent responses by chronic alteration of blood flow. Am $\mathcal{F}$ Physiol 1986; 251: H520-7.

30 Haworth SG. Pulmonary hypertension in childhood. Eur Respir F 1993; 6: 1037-43.

31 Schranz D, Zepp F, Iversen S, Wippermann C, Huth $R$ Zimmer B, et al. Effects of tolazoline and prostacyclin on pulmonary hypertension in infants after cardiac surgery. Crit Care Med 1992; 20: 1243-9.

32 Schranz D, Huth R, Wippermann C, Ritzerfeld S, Schmit FS, Delert H. Nitric oxide and prostacyclin lower FS, Delert H. Nitric oxide and prostacyclin lower suprasystemic pulmonary hypertension after carc

33 Sellden H, Winberg P, Gustafsson LE, Lundell B, Book K Frostell CG. Inhalation of nitric oxide reduced pulmonar hypertension after cardiac surgery in a $3.2 \mathrm{~kg}$ infant. Anesthesiology 1993; 78: 577-80.

34 Roberts JDJ, Lang P, Bigatello LM, Vlahakes GJ, Zapo WM. Inhaled nitric oxide in congenital heart disease. Circulation 1993; 87: 447-53.

35 Evans NJ, Archer LNJ. Doppler assessment of pulmonary artery pressure and extra-pulmonary shunting in the acute phase of hyaline membrane disease. Arch Dis Child 1991; 66: $6-11$.

36 Skinner JR, Boys RJ, Hunter S, Hey EN. Pulmonary and systemic arterial pressure in hyaline membrane disease. systemic arterial pressure in hyalin
Arch Dis Child 1992; 67: 366-73.

37 Walther FJ, Benders MJ, Leighton JO. Persistent pulmonary hypertension in premature neonates with severe respiratory distress syndrome. Pediatrics 1992; 90 899-904.

38 Mupanemunda RH, Silverman $\mathrm{M}$. Inhaled nitric oxide in respiratory distress syndrome. Pediatr Res 1994; 35: 346A

39 Bancalari E, Abdenor GE, Feller R, Gannon J Bronchopulmonary dysplasia: clinical presentation. f Pediatr 1979; 95: 819-23.
40 Goodman G, Perkin RM, Anas NG, Sperling DR, Hicks DA, Rowen M. Pulmonary hypertension in infants with bronchopulmonary dysplasia. $\mathcal{F}$ Pediatr 1988; 112: 67-72.

41 Abman SH, Griebel JL, Parker DK, Schmidt JM, Swanton $D$, Kinsella JP. Acute effects of inhaled nitric oxide in children with severe hypoxaemic respiratory failure. F Pediatr 1994; 124: 881-8.

42 Mupanemunda RH, Silverman $M$. Low-dose inhaled nitric oxide in infants with bronchopulmonary dysplasia. Pediatr Res 1994; 36: 31A.

43 DeBruin W, Notterman DA, Magid M, Godwin T, Johnston S. Acute hypoxaemic respiratory failure in infants and children: clinical and pathologic characteristics. Crit Care Med 1992; 20: 1223-34.

44 Davis SL, Furman DP, Costarino AT. Adult respiratory distress syndrome in children: associated disease, clinical course and predictors of death. $\mathcal{F}$ Pediatr 1993; 123: $35-45$.

45 Katz R, Pollack M, Spady D. Cardiopulmonary abnormalities in severe acute respiratory failure. $\mathcal{F}$ Pediatr 1984; 104: 357-64.

46 Zapol WM, Snyder MT. Pulmonary artery hypertension in severe acute respiratory failure. $N$ Engl f Med 1977; 296: $476-80$.

47 Swami A, Keogh BF. The injured lung: conventional and novel respiratory therapy. Thorax 1992; 47: 555-62.

48 Moler FW, Palmisano JM, Green TP, Custer JR Predictors of outcome of severe respiratory syncytial virus-associated respiratory failure treated with extracorporeal membrane oxygenation. $\mathcal{F}$ Pediatr 1993; 123: 46-52.

49 Guarin M, Day RW, Lynch JM, Vermon DD, Dean M. Inhaled nitric oxide improves oxygenation in paediatric patients with respiratory failure and pulmonary hypertension. Pediatr Res 1994; 35: 52A.

50 Rimar S, Gillis CN. Pulmonary vasodilation by inhaled nitric oxide after endothelial injury. F Appl Physiol 1992; 73: $2179-83$.

51 Petros AJ, Cox PB, Bohn D. Simple method for monitoring concentration of inhaled nitric oxide. Lancet 1992; 340: 1167

52 Downes MJ, Edwards MW, Elsey TS, Walters CL. Determination of a non-volatile nitrosamine using denitrosation and a chemiluminescence analyser. Analyst 1976; 101: 742-8.

53 Gustafsson LE, Leone AM, Persson MG, Wiklund ND, Moncada S. Endogenous nitric oxide is present in the exhaled air of rabbits, guinea pigs and humans. Biochem Biophys Res Commun 1991; 181: 852-7.

54 Stamler JS, Jaraki O, Osborne J, Simon DI, Keaney J, Vita $\mathrm{J}$, et al. Nitric oxide circulates in mammalian plasma primarily as an S-nitroso adduct of serum albumin. Proc Natl Acad Sci USA 1992; 89: 7674-7.

55 Miller OI, Celermajer DS, Deanfield JE, Macrae DJ. Guidelines for the safe administration of inhaled nitric Guidelines for the safe administration

56 Finer NN, Etches PC, Kamstra B, Tierney AJ, Peliowski A, Ryan CA. Inhaled nitric oxide in infants referred for extracorporeal membrane oxygenation: dose response. f Pediatr 1994; 124: 302-8.

57 Gerlach H, Rossaint R, Pappert D, Falke KJ. Time-course and dose-response of nitric oxide inhalation for systemic oxygenation and pulmonary hypertension in patients with adult respiratory distress syndrome. Eur $\mathscr{f}$ Clin Invest 1993; 23: 499-502. 